\title{
A carroça ao lado do avião: o direito à cidade metropolitana em Brasília
}

\author{
The wagon beside the airplane: the right \\ to the metropolitan city in Brasília
}

Benny Schvarsberg

\begin{abstract}
Resumo
A teoria do desenvolvimento desigual e combinado ajuda a entender o processo de metropolização de Brasília. Esse nexo, além das dimensões socioeconômicas próprias àquela teoria, possui dimensão urbanística: um urbanismo pautado pelo ideário do movimento moderno inscreveu-se na forma de um avião como matriz do território que se metropolizou. Derivações da metropolização periférica não lhe acompanharam fazendo contraponto paradoxal: surgem bem posteriormente, portanto mais atuais; quanto mais recentes, mais atrasadas e antigas se configuram, parecendo pertencer a tempos remotos ao urbanismo modernista, convivendo funcionalmente no território metropolitano. 0 texto utiliza o binômio Carroça \& Avião para a reflexão de políticas de reprodução de padrões de precariedade urbana expressas no primeiro termo fazendo parte do mesmo processo que garante privilégios a áreas bem providas da metrópole expressas no segundo termo.
\end{abstract}

Palavras-chave: metropolização; desenvolvimento desigual e combinado, direito a cidade; Brasília.

\begin{abstract}
The theory of combined and uneven development helps to understand the metropolization process of Brasilia. This nexus, in addition to the socioeconomic dimensions that are part of that theory, has an urban dimension: an urban design guided by the ideas of the modern movement was inscribed, in the form of an airplane, as the originating matrix of the territory that became a metropolis. Derivations of the peripheral metropolization have not accompanied it and have made a paradoxical counterpoint: they emerge much later and, the more recent they are, the more old-fashioned and archaic they are configured, seeming to belong to periods before the modern urbanism of the 20th century, coexisting in a functional manner in the metropolitan territory. In the article, we use the binomial Wagon \& Airplane to reflect on policies that reproduce urban precariousness patterns, expressed in the first term; they are part of the same process that ensures privileges to well-equipped areas of the metropolis, which are expressed in the second term.
\end{abstract}

Keywords: metropolization; combined and uneven development; right to the city; Brasilia. 


\section{Introdução}

A problemática urbana metropolitana e os dilemas do planejamento e gestão integrada de regiões e áreas metropolitanas têm renovada atualidade e relevância crescente nessas primeiras décadas do século XXI. Não obstante os avanços sociais e nos marcos legais da política urbana, no Brasil os dados do último censo nacional de 2010 do IBGE (Instituto Brasileiro de Geografia e Estatística) apontaram a continuidade da concentração da população, da desigualdade socioeconômica e da pobreza urbana nas periferias metropolitanas.

Essa questão se acentua e ganha contornos peculiares para a pesquisa urbana e regional quando focamos o caso de Brasília em um processo de crescimento que aprofunda a problemática do modelo de ocupação territorial de sua área metropolitana. Assinala-se a necessidade de considerar os obstáculos e constrangimentos à implementação de políticas públicas de planejamento e gestão territorial que logrem enfrentar, de forma integrada, as dificuldades conformadas ao longo de mais de meio século de constituição de uma complexa área metropolitana junto à nova capital.

0 desafio das abissais desigualdades entre Brasília e as cidades que compõem a sua área metropolitana demanda, aos pesquisadores, aos gestores públicos em diferentes níveis e aos diversos atores e segmentos sociais, a compreensão das lógicas enredadas nesse processo. E, no campo do reconhecimento de direitos que ofereçam conteúdos para novas políticas públicas, impõe-se a experimentação de novos instrumentos e conceitos que ponham em marcha os avanços legalmente estabelecidos tanto no Estatuto da Cidade, em 2001, como, sobretudo, mais recentemente no Estatuto da Metrópole, em 2015.

Por um lado, a reflexão proposta encontra estímulo num exercício de apropriação da lei do desenvolvimento desigual e combinado, designando a mistura de desenvolvimento e subdesenvolvimento em muitos países, especialmente nos periféricos, nos quais um setor moderno pode conviver - temporal e espacialmente, diríamos nós - com o mais atrasado; mesmo este funcionando como freio daquele, podem conviver de maneira combinada, resultando numa formação social particular, porém única. De filiação teórica tributária do pensamento do russo León Trotsky, nos últimos tempos visto como démodé e até com certo preconceito em face de históricos embates teóricos e ideológicos na tradição marxista, tal formulação, bem como desenvolvimentos teóricos que dela se apropriam, aplicando-a à realidade brasileira, como Fernandes (1955) e Oliveira (2003), oferece elementos analíticos promissores para a análise do processo de urbanização e metropolização de Brasília. Por outro lado, procura-se dialogar com a matriz teórica desenvolvida por Henri Lefebvre no conceito de Direito à Cidade em uma perspectiva ampliada voltada ao debate da questão metropolitana.

Em suma, oferecer uma contribuição ao debate da política e do planejamento regional e metropolitano, a partir da caracterização da metropolização desigual e combinada de Brasília, e apontar proposições na perspectiva do direito à cidade metropolitana constituem a motivação fundamental das reflexões sugeridas neste artigo. 


\section{Metropolização desigual e combinada de Brasília}

A lei do desenvolvimento combinado e desigual é uma referência teórica que compreende a ocorrência temporalmente simultânea de aspectos avançados e atrasados no processo de desenvolvimento econômico dos países. Ela aponta para uma forte mistura de atraso e modernidade, convivendo lado a lado, portanto espacialmente e no mesmo período; espaço e período nos quais um setor moderno pode conviver com o mais atrasado, embora este opere como limitante daquele, mas que, em conjunto, influenciem-se mutuamente, modificando-se e até formando um todo único, novo e próprio. Ela se revela especialmente nos países periféricos do sistema mundial, nos quais um setor extremamente moderno da economia pode existir de forma combinada com o mais atrasado, resultando numa formação social sem grandes contradições entre as classes dominantes. É uma das tentativas mais significativas de romper com o evolucionismo, a ideologia do progresso linear e o chamado eurocentrismo (Löwy, 1995).

Permitindo-nos um livre exercício de apropriação daquela referência teórica, proporemos que em uma mesma metrópole, um urbanismo moderno, que aqui chamaremos de Avião em alegoria à forma do plano piloto de Brasília, pode existir de forma combinada com urbanizações periféricas precárias e de padrões mais atrasados - cidades goianas do chamado "entorno" brasiliense, que aqui chamaremos também alegoricamente de Carroça, em contraponto tecnológico com o Avião. Carroça e avião convivem lado a lado em uma continuidade física, embora descosturada, no tecido desigual do mesmo território. Não obstante as enormes desigualdades, em ambos estão igualmente presentes algumas das grandes empresas atacadistas ${ }^{1}$ ou varejistas, implantando-se tanto no plano piloto e suas áreas adjacentes como na periferia metropolitana. Além do compartilhamento físico e temporal, tais empresas constituem um traço de simultaneidade e copresença que encontramos no território metropolitano, atendendo às populações de áreas nobres e pobres tanto do avião como da carroça ao lado, lucrando com ambas. ${ }^{2}$ Do ponto de vista do sentimento de pertencimento ao território, as populações da carroça se conectam cotidianamente bem mais com Brasília do que com Goiás: o território da Brasília metropolitana constitui nessa análise 0 seu território usado. ${ }^{3}$ Tais populações possuem um sentimento difuso de pertencimento, a nosso ver subalterno ou subordinado ao avião. Usando uma imagem alegórica, mais como "fuselagem", ou seja, ajudam a dar forma ao corpo do avião; elas não moram no avião, e seus registros documentais são goianos, mas cultivam o sentimento de pertencimento e de identidade territorial "brasiliense". Já a recíproca não é verdadeira: as populações do avião querem desconhecer as da carroça - no seu imaginário, são gente embrutecida e violenta ${ }^{4}$ - como seus vizinhos, a não ser como mão de obra para serviços domésticos, de segurança, limpeza e manutenção. As empresas privadas ${ }^{5}$ compradoras e vendedoras, especialmente para os órgãos públicos, dessa mão de obra farta e barata - um verdadeiro exército de serviços de reserva - são provavelmente os seus principais interlocutores para o acesso cotidiano ao avião. 
Simbolicamente e ao mesmo tempo lastreado em dados estatísticos, pode-se afirmar que quem comanda a economia metropolitana é 0 avião, fundamentalmente porque nele estão fortemente concentrados os empregos e 0 PIB. ${ }^{6}$ Ele atrai e "puxa" a carroça que é sua dependente, uma vez que boa parte da população da periferia metropolitana viaja diariamente de modo pendular em razão de trabalho e serviços, especialmente médicos hospitalares, no avião. Assim, a absoluta maioria dos brasilienses não reside no avião (mais de $90 \%$ da população do Distrito Federal mora fora do plano piloto), mas dele muitos, talvez a maioria, dependem direta ou indiretamente. Entretanto, avião não prescinde da carroça para se movimentar, tal como nos aeroportos, mesmo os grandes aviões precisam da ajuda imprescindível de pequenas carretas para reposicioná-los, pois aviões não dão marcha à ré. Portanto, apesar de profundamente desiguais - e até dessemeIhantes dado o fosso de condições de vida que parece condená-los a serem seres de espécies distintas - e de pertencerem aparentemente a diferentes épocas (moderna e remota), não é à toa que avião e carroça estão lado a lado no mesmo território e na mesma época; são interdependentes e não estão simplesmente um ao lado do outro, numa espécie de coexistência congelada, mas se articulam, se combinam e se amalgamam, configurando um todo, espacialmente contínuo e profundamente heterogêneo: o território metropolitano.

Estamos cientes de que o termo carroça, mais ainda em associação com o termo avião, carrega consigo uma carga de contraponto pejorativo, tal como carregam os termos subúrbio (no Brasil), periferia e entorno. É corrente na literatura crítica que esses termos remetam a noções de segregação e exclusão socioeconômica, política e cultural de populações urbanas. De fato, compreendemos que a dinâmica urbana e metropolitana construída historicamente em Brasília nas últimas cinco décadas soergueu uma urbanização sem urbanidade. ${ }^{7}$ Poderíamos até denominar "arrabaldes" aquelas áreas pobres do território ; termo usado até a primeira metade do século XX para designar as áreas mais distantes dos centros urbanos que se urbanizavam paulatinamente. Não seria, contudo, a designação que alteraria a perversidade social das realidades urbanas destituídas de direitos que constituem aquelas parcelas do território e sua população; quando muito serviria para mascará-la ou até ironizá-la, como ocorre, a nosso juízo, quando se nomeia, como Águas Lindas, ${ }^{8}$ um município que mal tem águas, e as que têm estão ambientalmente comprometidas e muito distantes de serem lindas.

Assim, assumimos e propomos, para efeito analítico da reflexão proposta, dois pressupostos básicos:

1) que nossa provocação com a formulação do binômio Carroça \& Avião é no sentido não só de evidenciar, mas também de acentuar o paradoxo da desigualdade combinada espacial e temporalmente;

2) que a periferia tem como vocação necessária, numa perspectiva de superação com reconhecimento de direitos, extinguir-se como tal e reincluir-se no território de modo qualificado; não como novo centro superando o anterior seria ingenuidade ou mistificação profética fazer crer que a carroça se tornar o novo avião pós-modernista -, mas como partes integradas de um todo e único corpo territorial metropolitano socialmente mais justo e ambientalmente menos desequilibrado. 
Além disso, ao usar figurativamente 0 paradoxo tecnológico da carroça e do avião, estamos sugerindo a reflexão de que políticas perversas de reprodução de padrões de precariedade urbana que se expressam no primeiro termo fazem parte orgânica do mesmo processo que garante privilégios a áreas bem providas e nobres da metrópole que se expressam no segundo termo. Apoiando-nos na teoria do desenvolvimento desigual e combinado, avaliamos que ela pode ajudar a entender a lógica que produziu e reproduz sistematicamente, há mais de cinco décadas, o processo de metropolização brasiliense. Sugerimos ainda que esse nexo, para além das dimensões socioeconômicas mais próprias à lei do desenvolvimento desigual e combinado, possui também uma dimensão urbanística que Ihe é organicamente vinculada. Um urbanismo original pautado pelo ideário do movimento moderno consagrado pelo Ciam - Congresso Internacional de Arquitetura Moderna - inscreveu-se na forma de um avião como matriz originadora de um território que se metropolizou. As derivações da metropolização periférica não só não Ihe acompanharam urbanisticamente como lhe fazem contraponto aparentemente paradoxal: elas surgem bem posteriormente, portanto são cronologicamente mais atuais; e, quanto mais recentes, mais atrasadas e antigas se configuram (grifo nosso), parecendo pertencer a remotas "eras" anteriores ao urbanismo modernista de meados do século XX.

A metropolização que combina a coexistência de "eras" distintas no mesmo território desigual constrói um dilema básico inclusive ao tombamento de Brasília como patrimônio cultural: não há como garantir a permanência de qualidades e privilégios urbanos restritos a uma porção da cidade cada vez mais enobrecida, elitizada e até preservada, por mais rigorosos que sejam os mecanismos legais locais, nacionais e internacionais. ${ }^{9}$ Nem se isolando fisicamente essa porção com uma redoma museológica de vidro, sob a qual só se circularia de pantufas para não ferir o tesouro patrimonial tombado, como seria ao gosto dos mais ortodoxos e conservadores preservacionistas. Emerge, então, a discussão da eficácia do projeto de preservação do avião limitado ao polígono tombado sem a expansão mínima das qualidades urbana, social, ambiental, cultural e educacional, em uma ótica metropolitana e regional que alcance e inclua necessariamente a periferia metropolitana destituída de direitos, aqui referida na alegoria tecnológica da carroça.

Institucionalmente, a responsabilidade pela maioria das políticas públicas urbanas incidentes na periferia metropolitana de Brasília ${ }^{10}$ é, primordialmente, do Governo Estadual de Goiás porquanto são majoritariamente municípios daquele Estado. A julgar pelo estado de abandono e baixo investimento dessas políticas nos últimos anos, a compressão do avião é mais provável do que a expansão de suas qualidades para a carroça, tornando quase uma condicionalidade para a sustentabilidade do avião, a médio e longo prazo, a extensão de alguns de seus privilégios para a carroça. Contudo, entendemos que essa extensão do ponto de vista institucional somente encontraria viabilidade por meio de um esforço político e financeiro concatenado e interfederativo, envolvendo necessariamente o Governo do Distrito Federal, o Governo do Estado de Goiás e o Governo Federal em um novo arranjo institucional de política metropolitana. 
Figura 1 - Mapa com inserção territorial de Brasília na Ride - Região Integrada de Desevolvimento Econômico com destaque para a Área Metropolitana de Brasília

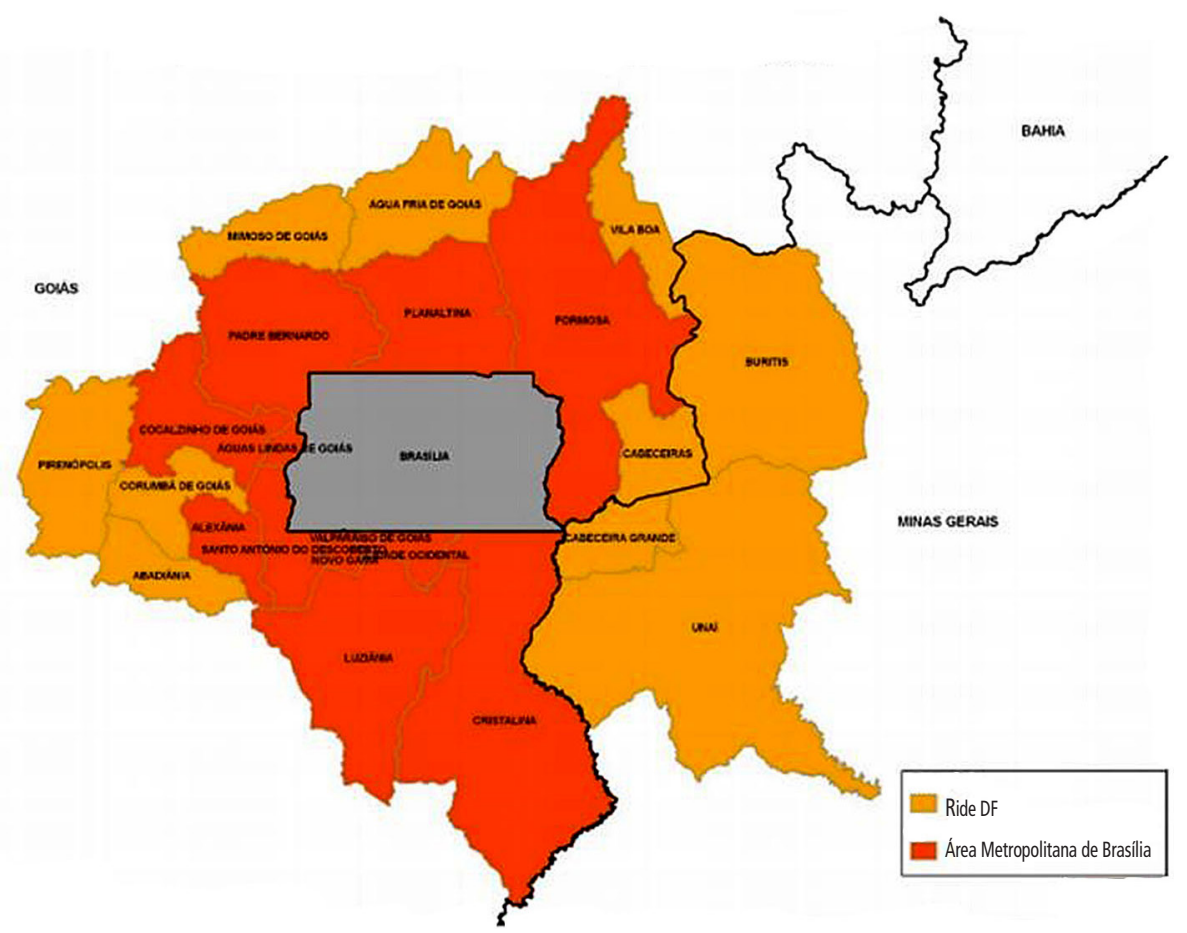

Fonte: Codeplan (2014).

Os dilemas colocados põem em xeque a efetividade do conjunto das políticas públicas incidentes na AMB - Área Metropolitana de Brasília, especialmente transportes públicos, uso do solo, habitação e saneamento básico, demandando, para a construção da agenda metropolitana, um triplo movimento constituído por: a) uma política redistributiva para enfrentar as profundas desigualdades territoriais; b) um planejamento e gestão metropolitana integrados de inclusão socioterritorial; e c) um fundo de justiça territorial que ofereça um lastro financiador para a implementação dessa política, planejamento e gestão integrada.

\section{Aportes teóricos da lei do desenvolvimento desigual e combinado nos processos de industrialização, urbanização e metropolização}

Um dos pressupostos presentes na lei do desenvolvimento desigual e combinado, que constitui um raciocínio aparentemente contraditório, é o de que, se um país começa a se industrializar tarde, irá adotar as indústrias mais modernas existentes na altura; logo, a pouca indústria que obterá será altamente 
desenvolvida, podendo conviver com traços econômicos de épocas remotas. $E$ que esses elementos se combinam mutuamente. Nessa perspectiva, por exemplo, a escravidão foi um elemento importante do desenvolvimento do capitalismo no século XIX (Löwy, 1995).

Para aplicar o pressuposto à nossa reflexão, é mister considerar que a industrialização é fundamental para entender o processo de urbanização brasileira no século $\mathrm{XX}$, assim como a expulsão da população do campo, em decorrência da estrutura fundiária altamente concentradora de terra nas mãos de poucos, bem marcada pelo latifúndio predominante na paisagem rural brasileira; muita terra nas mãos de poucos proprietários, ao contrário de muitos proprietários de parcelas menores de terra no padrão fundiário predominante de países europeus que realizaram suas reformas agrárias nos séculos XVIII, XIX e XX.

Operando o nexo entre desigualdade, industrialização e urbanização, Milton Santos tratou a urbanização desigual levando em conta as categorias de tempo e espaço. Lembrando que a urbanização moderna acompanhou a Revolução Industrial, ele mostrou que a tendência era fazer a correlação com os países subdesenvolvidos. Traçando um paralelo entre industrialização e urbanização, ele demonstrou o equívoco da tese de que a urbanização dos países subdesenvolvidos seria uma repetição da urbanização dos países desenvolvidos (Santos, 1994).

Importante esforço teórico em torno da simultaneidade dialética de diversos estágios históricos vem dos estudos de Fernandes (1968 e 1995), voltados à compreensão do desenvolvimento capitalista nos países periféricos e das formas políticas assumidas pela dominação burguesa nesses territórios. Rejeitando qualquer perspectiva analítica linear "etapista", assim como o esquematismo "dualista" calcado em referências históricas europeias e norte-americanas, esse autor elabora, com 0 conceito de "capitalismo dependente", uma natureza histórica peculiar na formação e no desenvolvimento do capitalismo nos países localizados na "periferia" do sistema que aponta uma apropriação particular da lei do desenvolvimento desigual e combinado. A realidade brasileira se constituía em uma totalidade dialeticamente contraditória claramente sintetizada na passagem:

A inegável desigualdade das formas de produção coexistentes e seus efeitos sobre 0 estilo de vida das populações do campo ou sobre o desenvolvimento econômico regional tem levado alguns cientistas sociais a interpretações dualistas rígidas. [...] a articulação de formas de produção heterogêneas e anacrônicas entre si preenche a função de calibrar 0 emprego dos fatores econômicos segundo uma linha de rendimento máximo, explorando-se em limites extremos o único fator constantemente abundante, que é o trabalho - em bases anticapitalistas, semicapitalistas ou capitalistas. Por isso, estruturas econômicas em diferentes estágios de desenvolvimento não só podem ser combinadas organicamente e articuladas no sistema econômico global. Sob o capitalismo dependente, a persistência de formas econômicas arcaicas não é uma função secundária e suplementar. A exploração dessas formas e sua combinação com outras, mais ou menos modernas e até ultramodernas, fazem parte do "cálculo capitalista". (Fernandes, 1968, pp. 64-65) 
Nesse esforço de apropriação teórica daquela lei, o "arcaico" não pode ser visto como vestígios de outra época, que funciona como entrave ao desenvolvimento das regiões onde está presente; é a presença de elementos "anticapitalistas" e "semicapitalistas" que produziria funcionalidade ao capitalismo nas áreas dependentes. 0 "arcaico", nessa leitura, não opera como contraponto ao "moderno", mas como seu complemento social e historicamente necessário. É precisamente no sentido da vitalidade do sistema capitalista imperialista que ocorria necessariamente a utilização de formas não capitalistas em inúmeras localidades do mundo. Logo, a história não poderia repetir suas etapas de desenvolvimento nos países atrasados, não há como fazer coincidir os seus tempos: as estruturas socioeconômicas, culturais e políticas dos países capitalistas hegemônicos absorvem estrategicamente as estruturas dos países subcapitalistas, semicapitalistas ou de capitalismo dependente, submetendo-as a seus próprios ritmos; em última análise, subordinando-as aos seus interesses. Para Fernandes (1995), o capitalismo selvagem, forma assumida pelo capitalismo nos países dependentes, não reproduz o passado; assim, a "burguesia nacional" seria uma "digna descendente da 'burguesia clássica'", no sentido que ela era "tão útil para a continuidade e o aperfeiçoamento do capitalismo" quanto haviam sido as burguesias dos países originários em tempos pretéritos.

Outro aporte fundamental na linha desse debate teórico pode ser encontrado na contribuição de Oliveira (2003), que demonstra a funcionalidade possibilitada pelo "arcaico" ao desenvolvimento do "moderno" no capitalismo brasileiro. Do ponto de vista territorial, as estruturas "arcaicas" do campo, longe de significarem entraves ao desenvolvimento dos setores "dinâmicos" da economia, como propunham adeptos do esquema "dualista" criticado por Fernandes referido acima, em face do baixo custo da força de trabalho rural que diminuía ao máximo o custo com os alimentos nas cidades e do enorme êxodo rural que criava o "exército de reserva" de assalariados, para Oliveira essas estruturas também operavam como estímulo à produção industrial e à acumulação do capital.

Outra referência que se materializa no espaço construído, ilustrado por Oliveira como prática social que expressa essa funcional combinação do "arcaico" com o "moderno", está na chamada autoconstrução das habitações dos trabalhadores. Ele exemplifica claramente como na tradição das classes trabalhadoras no Brasil parte significativa das suas moradias foi construída pelos próprios proprietários, em muitos casos em terrenos e loteamentos ilegais diríamos nós, para isso lançando mão de seus dias de folga e de fins de semana e valendo-se de mutirões de cooperação. Dessa prática resulta um bem que é a habitação, que se produz pelo que ele denomina supertrabaIho ou trabalho não pago. Esse bem, mesmo não sendo desapropriado pelo setor privado da produção, de fato contribui para aumentar a taxa de exploração da força de trabalho: 0 seu resultado - a casa - reflete-se numa baixa aparente do custo de reprodução da força de trabalho do qual os gastos com habitação são componente importante para deprimir ainda mais os salários reais pagos pelas empresas. Nessa lógica, o que parece uma operação de sobrevivência de práticas de "economia natural" dentro das cidades se insere perfeitamente 
bem com um processo de expansão capitalista, cujas base e dinamismo se situam na intensa exploração da força de trabalho.

Esse processo, descrito em apenas algumas de suas formas e níveis diversos, caracteriza o modo de acumulação global próprio da expansão do capitalismo no Brasil pós anos 1930. Reinterpretando, a nosso ver, a proposição de Trotsky, Oliveira mostra como a desigualdade de que se configura esse processo é não só desigual, mas é combinada e produto, antes de uma base capitalista de acumulação razoavelmente pobre para sustentar a expansão industrial e a conversão da economia pós-1930, do que da existência de setores "atrasados" e "modernos" (Oliveira, ibid.). Assim, na crítica à razão dualista de Oliveira, "arcaico" e "moderno" não se constituem em elementos que produzem duas realidades distintas; mas proporcionam uma natureza única, peculiar e dialética à estrutura societal dos países que chegaram com atraso na corrida industrial capitalista.

A Rússia às vésperas da revolução de 1917, analisada por Trotsky, era detentora de tecnologia fabril equiparada e às vezes até superior aos países avançados, que se combinava e coexistia com a presença de uma estrutura agrária similar em grande parte à de dois ou três séculos antes. Essa análise de que a possibilidade do veloz progresso ocorrido na indústria russa foi "precisamente determinada pelo estado atrasado do país" (Trotsky, 1977, p. 28) comparece também na leitura de Oliveira, ao apontar como o crescimento capitalista industrial brasileiro deu-se sob, e a partir de, uma base econômica portadora de vários elementos bastante rudimentares.
Além disso, a urbanização que vai constituir o território que foi objeto de um processo de metropolização a partir da construção de Brasília foi fruto de complexas correlações de forças expressas em uma decisão de Estado, com todas as suas lógicas e contradições, como pode ser aprofundado na interpretação de vários autores (Schmidt, 1985 e Bicca, 1985). Mas é também, sob distintas formas, tributária da industrialização. Tanto a industrialização é um dos motes do Plano de Metas do presidente Juscelino Kubitschek (1955-1959), particularmente a indústria automobilística como um de seus ícones principais, quanto o urbanismo modernista tem clássico suporte na mobilidade baseada no automóvel. 0 arquiteto Lucio Costa, vencedor do certame que escolheu 0 Plano Piloto de Brasília, afirma claramente, no memorial descritivo de seu projeto, que utilizou em sua concepção as modernas técnicas rodoviárias, como o cruzamento de vias em desnível evitando semáforos, assim como um eixo rodoviário atravessando longitudinalmente toda a cidade a fim de dar-lhe fluidez. 0 seu relatório apresenta inúmeras alusões à indústria automobilística e ao automóvel, propondo inequivocamente uma cidade que desfrutaria de franca mobilidade por automóvel, como se explicita numa das mais reproduzidas e emblemáticas passagens no item 8 de seu texto:

\footnotetext{
Não se deve esquecer que o automóvel, hoje em dia, deixou de ser o inimigo inconciliável do homem, domesticou-se, já faz, por assim dizer, parte da família. (Relatório, 1957 apud Depha, Codeplan, 1991)
}

Assim, a cidade se constituiu para ser a capital do País como essencialmente a sede política e administrativa nacional e não teve, 
a nosso juízo, nem na origem, nem no seu desenvolvimento posterior, uma consistente e eficaz política pública de industrialização. Talvez 0 que se possa chamar de sua principal indústria, segundo alguns estudiosos do desenvolvimento econômico local (Couto et al., 1992), tenha sido, e continua sendo a nosso ver, a da construção civil em função da reconhecida grande dinâmica imobiliária da cidade. Contudo, 0 projeto de industrialização, básico no Plano de Metas de JK, não era necessariamente contraditório com o projeto da nova capital com função primeira político-administrativa.

Embora o autor do projeto urbanístico do Plano Piloto em sua concepção refute peremptoriamente a ideia de uma grande metrópole: "A Brasília não interessa ser grande metrópole", afirma ele textualmente como se verá abaixo, em nenhuma referência demonstra ser refratário nem à industrialização nem tampouco à metropolização. Ao contrário, no mesmo texto ele reconhece a existência de uma população metropolitana expressiva. $E$, mais do que isso, sugere a necessidade de núcleos industriais em áreas próximas à capital (grifo nosso) na Conclusão do Relatório Brasília Revisitada, 1985-1987: complementação, preservação, adensamento e expansão urbana (apud Costa 1986, p. 68):

0 "quantum" populacional atingido pela abertura à ocupação dessas novas áreas, pelos adensamentos previstos, pela ocupação residencial multifamiliar nas margens das vias de ligação entre Brasília e as satélites, pelo adensamento controlado desses núcleos e pela implantação da Samambaia, deve ser considerado a população limite para a capital federal, a fim de não desvirtuar a função primeira - político-administrativa - que Ihe deu origem. A Brasília não interessa ser grande metrópole.

Como nossa estrutura econômico-social induz à migração de populações carentes para os grandes centros urbanos, é essencial pensar-se desde já no desenvolvimento, em áreas próximas à capital de núcleos industriais capazes de absorver, na medida do possível, essas migrações com efetiva oferta de trabalho.

Malgrado as indicações do autor do projeto do Plano Piloto de Brasília, e do debate crítico dos estudiosos do desenvolvimento econômico local, efetivamente não ocorreu, no primeiro meio século de Brasília, uma industrialização minimamente expressiva. Nem ao menos uma industrialização tardia que convivesse com traços econômicos de uma "era" remota, por mais que traços de uma economia remota possam ser encontrados ainda hoje nos remanescentes de antigas fazendas e propriedades dos municípios goianos de Formosa, Planaltina e Luziânia, que são os originadores do território onde foi demarcado o quadrilátero do atual Distrito Federal. Tampouco as iniciativas do governo local com programas como o Pró-DF ${ }^{11}$ de estímulo econômico a empreendimentos de pequenos e médios empresários lograram resultados de impacto significativo numa economia marcada pela ampla hegemonia do setor terciário de serviços (públicos e privados). Ao largo desse verdadeiro vazio de industrialização, ${ }^{12}$ desenvolveu-se uma particular urbanização e junto a ela um processo de metropolização. E foi esse 
processo que estabeleceu a relativa e peculiar convivência e continuidade territorial, não obstante padrões de distâncias de cerca de 50 quilômetros entre espaços urbanos de modernidade mais velhos e espaços urbanos periféricos metropolitanos mais jovens cujas precariedade e configuração possuem traços que remetem a épocas remotas.

Algumas figuras a seguir buscam ilustrar esse processo.

Figura 2 - Projeto do Plano Piloto de Brasília, no traço original para o concurso que escolheu o projeto (Arquivo Público do Distrito Federal)

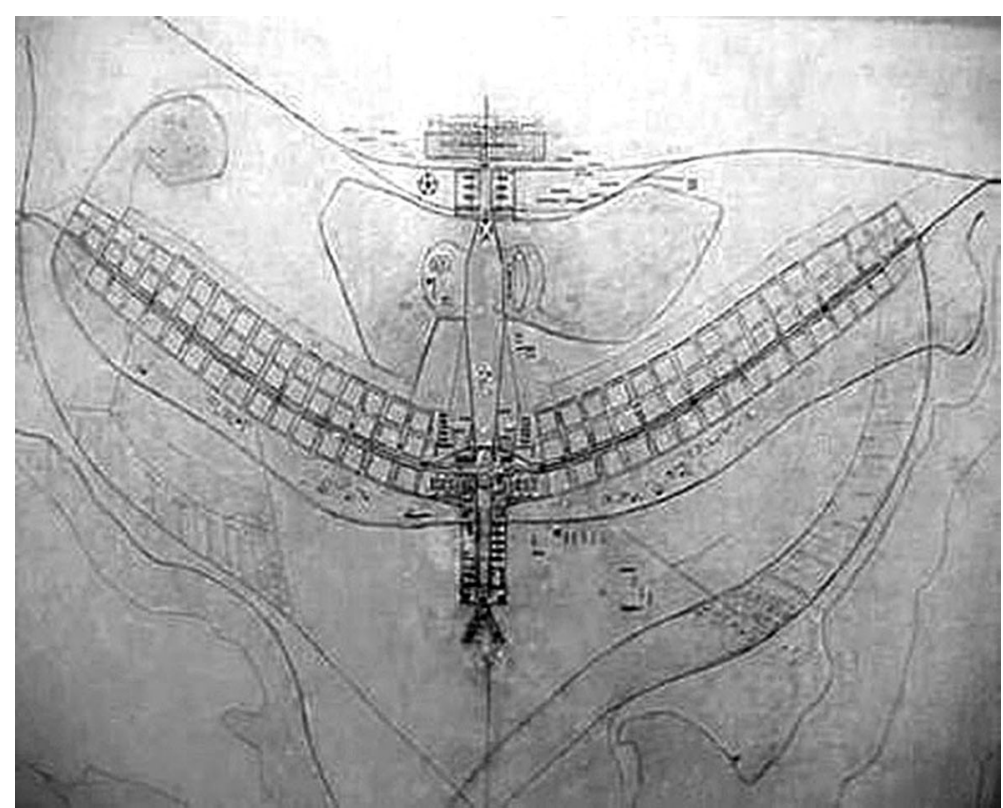


Figura 3 - Projeto do Plano Piloto de Brasília com alterações e adaptações posteriores, sugeridas pelos membros do júri para a sua implantação (Arquivo Público do Distrito Federal)

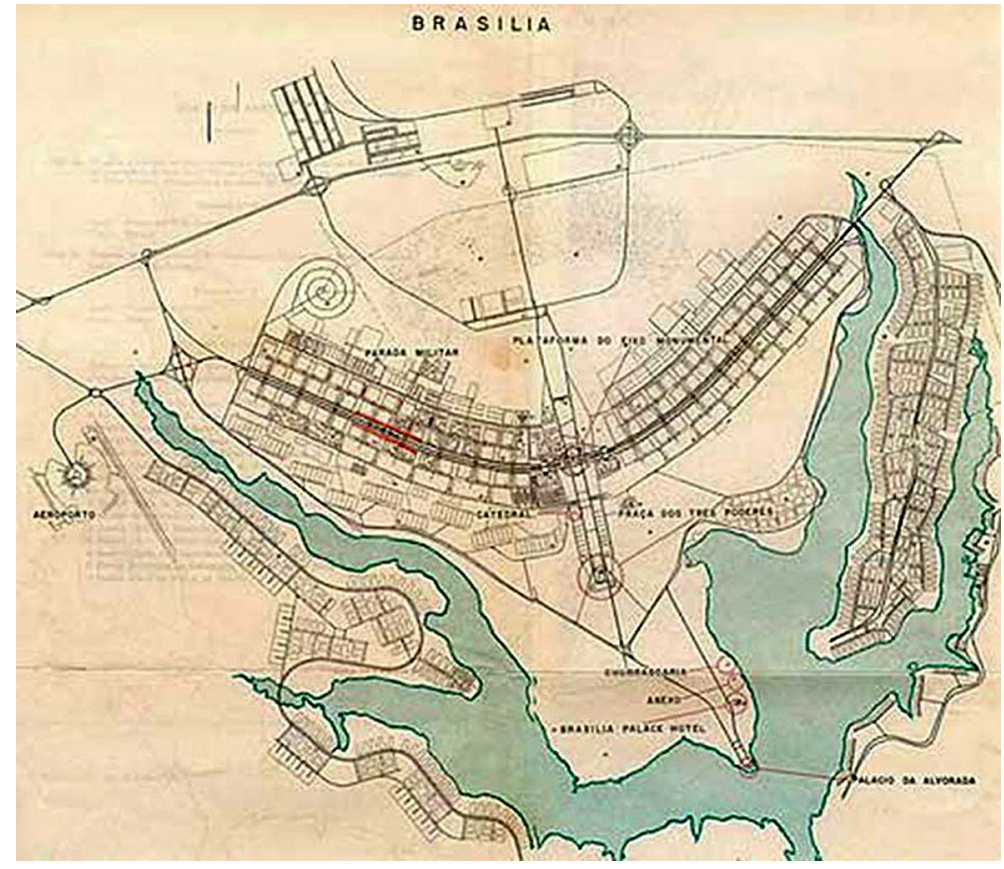

Figura 4 - Construção de Brasília, dos anos 1960 (Arquivo Público do Distrito Federal)

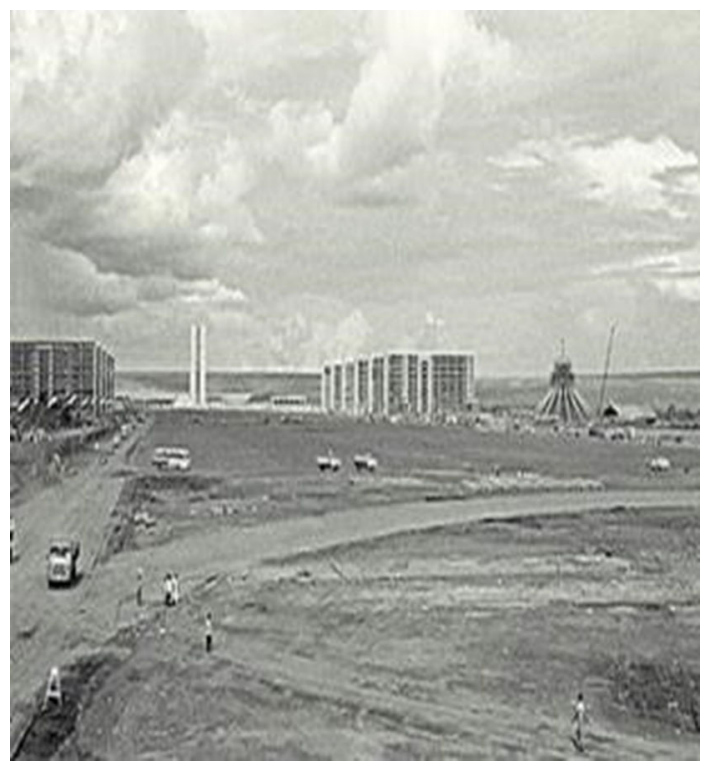


Figura 5 - Construção de Brasília, dos anos 1970

(Arquivo Público do Distrito Federal)

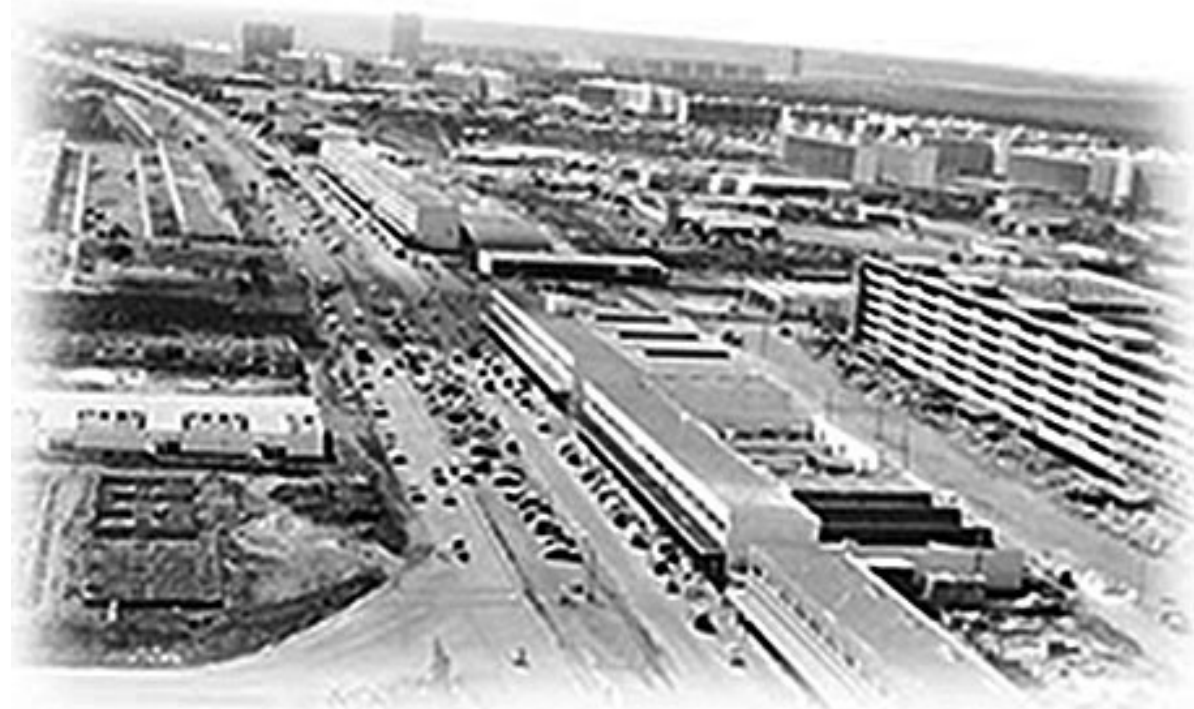

Figura 6 - Avião sobrevoando a esplanada dos ministérios e área central da cidade dos anos 1980 (Arquivo Público do Distrito Federal)

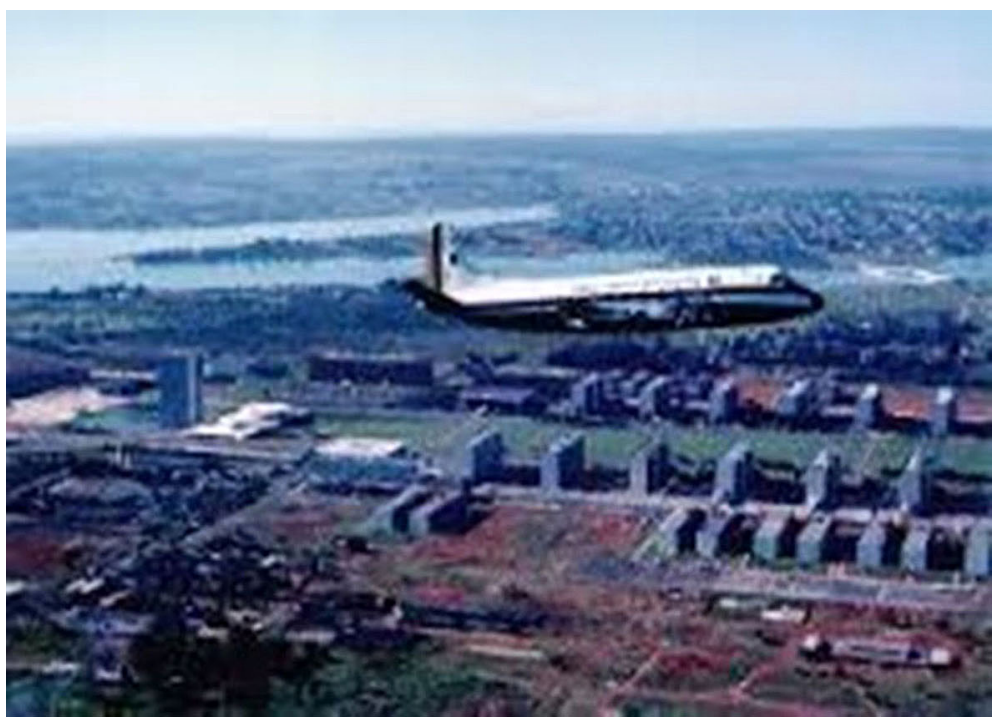


Figura 7 - Valparaiso/GO, anos 2000:

ruas sem calçadas com pavimentação deteriorada e lixo não recolhido, com destaque para a carroça convivendo com carros, pedestres, ciclistas e caminhões (Jornal Correio Brasiliense)

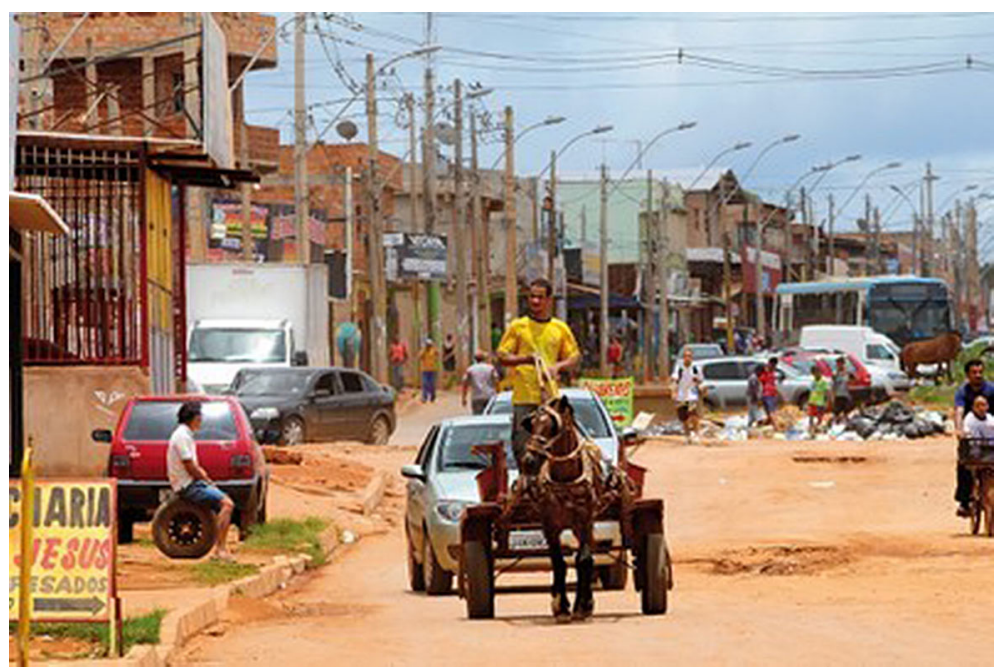

Figura 8 - Valparaiso/GO, anos 2000:

população local sendo reprimida violentamente pela polícia, ao realizar manifestação pública reivindicando melhorias urbanas (Jornal Correio Brasiliense)

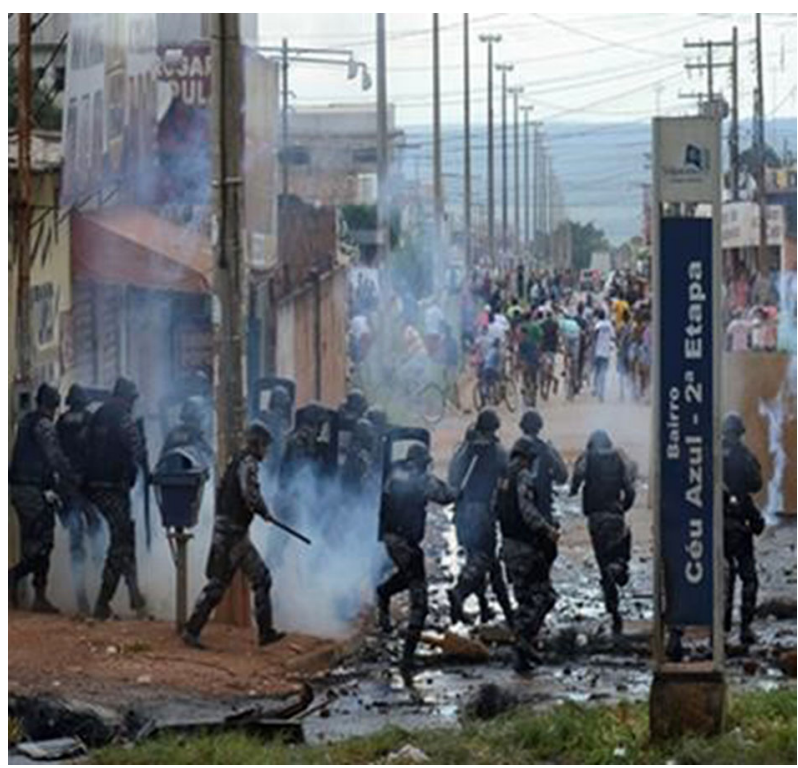




\section{Os lentos carroceiros e os velozes espaços do avião na metropolização desigual e combinada, interdependente e complementar: o potencial emergente/insurgente da periferia e o direito à cidade metropolitana}

A atitude predominante dos privilegiados ocupantes do avião - que constitui o centro do território metropolitano -, especialmente seus moradores e gestores, é de uma "quase indiferença" pela existência dos ocupantes da carroça; conquanto saibam que muitos, a maioria deles, frequentam o avião até porque sabem da sua subordinação e dependência em matéria de trabalho, emprego e serviços. Imaginam mesmo que aqueles periféricos "carroceiros" não existiriam não fosse a irradiação dos potentes e atraentes motores do avião moderno e cosmopolita, de cujos espaços nobres e cada vez mais valorizados se orgulham de ser ocupantes. E chegam até a olhar de soslaio, com boa dose de desconfiança e receio, quando, em momentos de viagem rodoviária interestadual em carros particulares, passam pela carroça (cruzando bairros e cidades periféricas) o mais rápido possível pelos quebra-molas e placas que alertam para diminuir a velocidade pois se está atravessando area urbana; com uma desqualificação naturalizada porque periférica, mas persistentemente urbana.

Já os carroceiros na periferia metropolitana reconhecem cotidianamente a sua condição de dependência e precariedade, mas desconhecem em grande medida a sua força e seus direitos à cidade metropolitana, distante ainda de serem reconhecidos pelos do avião. Seria inconcebível pensar em insurgências? Em consciência crítica e protagonismo político na reivindicação e luta pelo reconhecimento de direitos de cidadania por parte dos carroceiros periféricos metropolitanos? Dialogando com esses questionamentos, volta e meia é veiculado pela mídia da capital um noticiário que dá conta de manifestações de protestos como, por exemplo, a queima de pneus na rodovia da periferia de Brasília (Figura 7), por conta de demandas de infraestrutura urbana como asfalto, saneamento básico, energia elétrica e principalmente transporte coletivo e suas tarifas, do qual depende aquela população no seu deslocamento diário. ${ }^{13}$ Constituem, invariavelmente, reinvindicações de acesso a serviços, infraestrutura e equipamentos urbanos e podem ser vistos como prenúncios, ainda que esparsos e desorganizados, do potencial de avanço daquela consciência crítica na perspectiva do direito à cidadania metropolitana.

Nos anos 1995-1998, em resposta às visões preconceituosas contra carroceiros que circulavam em Brasília, o então governador do Distrito Federal, Cristovam Buarque, ${ }^{14}$ fez publicamente alusão à necessidade daqueles carroceiros, que habitualmente à época coIhiam lixo nas vias de Brasília, terem o direito não somente de circular livremente na cidade, mas de cumprir um papel social relevante e até complementar ao serviço de limpeza pública. Para além dos efeitos práticos positivos para a cidade da coleta de lixo pelos carroceiros, sobrepujando eventuais efeitos negativos sobre 0 trânsito ou à segurança pública, o governador defendeu a necessidade de meios modernos coexistirem social e tecnologicamente com 
aqueles meios antigos tradicionais - ou "arcaicos", como são vistos pela população do avião. Seu argumento era que ambos fizessem parte da mesma modernidade e fossem portadores de direitos de cidadania. Ampliando o debate, em termos republicanos e democráticos, não era aceitável a visão excludente de que eram extemporâneas e indesejáveis sua coexistência e convivência pacifica no espaço público da cidade modernista desenhada sim para carros "velozes" e não para carroças e homens "lentos". Tomando como inspiração este último termo, cabe resgatar o conceito-personagem dos homens lentos, ${ }^{15}$ elaborado teoricamente por Milton Santos, que ajuda a adensar essa reflexão da leitura crítica das contradições e da lógica profundamente dialética expressa nessa coexistência territorial metropolitana desigual e combinada.

Já o sentido que buscamos imprimir no que aqui chamamos de Direito à Cidade Metropolitana decorre de uma derivação do conceito de Direito à Cidade, cunhado por Henri Lefebvre $^{16}$ e muito difundido na sociologia urbana. Esse conceito foi elaborado teoricamente na sua obra-manifesto Le Droit à La Ville, publicado poucos meses antes das explosivas manifestações de maio de 1968. Nela, Lefebvre critica as posições deterministas e metafísicas do urbanismo modernista: aprofunda o debate sobre o reducionismo da lógica de que os problemas da sociedade possam ser todos reduzidos a questões espaciais, mais ainda "resolvidos" no projeto de um arquiteto. Mas a crítica a um urbanismo de conteúdo ideológico positivista certamente não se reduz à questão de ignorar os limites da capacidade de o planejamento racionalista abstrato transformar a realidade.
Bem mais do que acusar o equívoco dos resultados, Lefebvre vai buscar acusar o caráter alienante da própria pretensão de tornar os problemas urbanos equacionáveis em questões de natureza meramente administrativa, técnica e científica, pois ela mantém um aspecto fundamental da alienação dos cidadãos: o fato de serem mais objetos do que sujeitos do espaço social e frutos de relações econômicas de dominação e de políticas urbanísticas por meio das quais o Estado ordena e controla a população. Na perspectiva lefebvriana, o Estado autoritário planificador - e sua leitura sugere certa simbiose entre os dois termos que grifamos - pode até eventualmente resolver necessidades materiais, como moradia e transporte, mas também priva as pessoas da condição de sujeitos históricos da construção da sua própria cidade.

Assim, a elaboração conceitual presente no conceito de Direito à Cidade remonta a bem mais do que a construção de moradias e ampliação generalizada do acesso a esse e outros bens materiais; ou mesmo ao direito de ir e vir, para toda população urbana. Isso seria trivial demais, além de reducionista. Lefebvre politiza a produção social do espaço e localiza o direito à cidade na sua luta pelo direito de criação e plena fruição do espaço social. Com isso, avança em concepções de cidadania que vão para além de direitos básicos, como o de voto e expressão verbal; está tratando de formas de democracia direta, de controle direto das pessoas sobre a forma de habitar e de transformar a cidade, produzida como obra humana coletiva em que cada indivíduo e comunidade têm preservados espaços para manifestar sua diferença.

Comparecendo nesse debate a partir da matriz lefebvriana, Harvey (2013) analisa 
as grandes manifestações de rua nas cidades brasileiras em junho de 2013, provocadas originalmente pelo aumento de $R \$ 0,20$ centavos na tarifa dos transportes públicos em São Paulo, propondo que:

0 direito à Cidade não pode ser concebido como simples direito de visita ou retorno às cidades tradicionais [...] pode ser apenas formulado como renovado e transformado direito à vida urbana. A liberdade da cidade é muito mais que um direito de acesso àquilo que já existe: é o direito de mudar a cidade mais de acordo com o desejo de nossos corações. A questão do tipo de cidade que desejamos é inseparável da questão do tipo de pessoa que desejamos nos tornar. A liberdade de fazer e refazer a nós mesmos e às nossas cidades é um dos mais preciosos de todos os direitos humanos.

Identificamo-nos com essa perspectiva de análise, entretanto ponderamos que a ideia mesma do Direito à Cidade Metropolitana não pode ser lida como simples ampliação do Direito à Cidade à escala metropolitana. De um lado, aponta-se, sim, para uma ampliação territorial de direitos e deveres por parte do estado e da sociedade. Mas, de outro, o que se coloca é a ressignificação do sujeito desse direito em direção a uma cidadania metropolitana; sobretudo com respeito ao reconhecimento dos direitos de cidadania e protagonismo dos periféricos e dos excluídos territorialmente das melhores condições e oportunidades dos centros metropolitanos.

Assim, é precisamente no campo do direito à cidade metropolitana que pode se vislumbrar, metaforicamente, as possibilidades da lenta carroça se aproximar do veloz avião. Tal como na clássica fábula da tartaruga e a lebre de Esopo, ${ }^{17}$ sugere-se aqui que a corrida da carroça brasiliense periférica metropolitana está bem mais próxima àquela da tartaruga "fundista" do que a da lebre "velocista". ${ }^{18}$ Ou seja, lenta como os homens lentos, de longo prazo e muito fôlego, nesse sentido de "fundista": no largo horizonte de lutas e batalhas de conquista do reconhecimento de direitos que aqui sintetizamos no Direito à Cidade Metropolitana. E não de "velocista", na ilusão de acreditar que iluminados dirigentes das classes dominantes, ou mesmo déspotas esclarecidos, tomados de inusitada consciência crítica, serão capazes de acelerar o reconhecimento daqueles direitos e de promover, na velha tradição tecnocrática top down, políticas públicas urbanas transformadoras da metropolização desigual e combinada. Até porque Brasília, desde suas origens e ao longo de seus primeiros cinquenta anos, teve seu processo de implantação e expansão territorial marcado pela tradição de políticas e ações dirigidas e coordenadas fundamentalmente pelo Estado; o que poderia ter sido fator diferencial de promoção de uma urbanização socialmente mais justa e inclusiva, promotora do Direito à Cidade, resultou, notoriamente, no inverso: uma das cidades de mais elevados graus de desigualdade, segregação e exclusão territorial de todo quadro metropolitano brasileiro.

\section{À guisa de conclusão}

A lei do desenvolvimento desigual e combinado e suas apreensões na leitura histórica da realidade brasileira oferecem pistas para uma leitura dialética da metropolização brasiliense na provocação aqui proposta no binômio tecnológico Carroça \& Avião. A aparente configuração 
de espaços e tempos modernos e remotos, convivendo proximamente em diferentes lugares do mesmo território e da mesma época, remete-nos à constituição de amálgamas sociais e territoriais complexos, complementares, contraditórios e interdependentes. Tais amálgamas renovam desafios teóricos para a reflexão de dilemas urbanísticos contemporâneos que aprofundam, por exemplo, a problemática da fragmentação versus coesão social, no território nas pesquisas sobre dispersão urbana (Reis, 2009), e o modelo territorial expresso na noção de "colcha de retalhos" (Medeiros, 2014).

0 paradoxo da desigualdade combinada espacial e temporalmente carrega, nas entranhas e lógicas de suas contradições, um potencial transformador numa hipótese de superação: uma outra inclusão é possível no território, de modo qualificado, como partes integradas de um todo, diferenciado e heterogêneo, mas único corpo territorial metropolitano; não simplesmente um lado a lado de coexistência congelada, mas uma nova combinação, repactuando e reconfigurando o heterogêneo e contínuo território metropolitano. Nessa perspectiva, o conceito central do direito à cidade metropolitana, que assenta bases no novo marco metropolitano brasileiro, ${ }^{19}$ demanda a emergência insurgente do papel dos lentos carroceiros destituídos de direitos, assumindo um protagonismo metropolitano em um arranjo institucional até então inexistente.

Na perspectiva de uma agenda de política pública metropolitana atravessando as políticas urbanas federais, estaduais e distritais, incidindo na AMB, conclui-se reforçando a consistência da demanda histórica por aquele triplo movimento constituído por: a) uma política metropolitana redistributiva que reconheça a profunda desigualdade socioterritorial; b) um planejamento e gestão metropolitana integrado, de natureza redistributiva e de reconhecimento de direitos; e c) um fundo metropolitano, que preferimos chamar fundo de justiça territorial, que ofereça lastro financiador para essa política, planejamento e gestão metropolitana integrada. Experiências contemporâneas na dimensão do planejamento e gestão metropolitana integrada das assembleias metropolitanas de Lisboa/Portugal, ou mesmo a mais próxima do recente plano metropolitano de Belo Horizonte/MG, constituem "espaços de esperança" (Harvey, 2000), que apontam para a possibilidade de novas práticas de conquista da garantia e do reconhecimento da presença diversificada e plural da periferia - especialmente de movimentos sociais de mobilidade urbana e moradia - nas decisões da política, do planejamento e da gestão metropolitana.

\section{Benny Schvarsberg}

Universidade de Brasília, Faculdade de Arquitetura e Urbanismo, Departamento de Projeto, Expressão e Representação. Brasília, DF/Brasil.

benny@unb.br 


\section{Notas}

(1) Empresas que ilustram essa lógica são, por exemplo, as duas maiores redes de móveis e eletrodomésticos (Ricardo Eletro e Novo Mundo) que possuem cada uma cerca de 100 lojas vendendo os mesmos produtos espalhadas em todo o Distrito Federal e nas cidades de Goiás que constituem a periferia metropolitana de Brasília.

(2) Vejam-se as matérias "A Máquina de Vendas Ricardo Eletro chega aos 25 anos, com faturamento anual de R\$ 10 bilhões, 1.100 lojas em 442 cidades e 30 mil funcionários" (Jornal Hoje em dia, de 26/1/2016); e "Maior varejista de Goiás, Novo Mundo não para de crescer" (Jornal O Popular, de $16 / 2 / 2014)$.

(3) "O território é o chão e mais a população, isto é, uma identidade, o fato e o sentimento de pertencer àquilo que nos pertence. $O$ território é a base do trabalho, da residência, das trocas materiais e espirituais e da vida, sobre as quais ele influiu. Quando se fala em território deve-se, pois, de logo, entender que está se falando em território usado, utilizado por uma população". (Santos, 2003)

(4) São frequentemente alardeados pela mídia os índices alarmantes de violência que criam e aprofundam o estigma que o próprio termo "entorno" já possui, vinculando-o a um imaginário de periferia com violência e criminalidade semelhante ao da Baixada Fluminense no Rio de Janeiro.

(5) Os contratos de prestação de serviços de segurança, limpeza e manutenção, nos quais é oferecida mão de obra terceirizada aos ministérios e órgãos públicos federais e do Distrito Federal, alcançam altos valores e são disputados por empresas com registro assentado no Distrito Federal tradicionais nesse ramo altamente lucrativo pelo contraste entre os valores recebidos pelas empresas e os pagos aos trabalhadores.

(6) A discrepância entre o Produto Interno Bruto - PIB do Distrito Federal e dos municípios vizinhos componentes da periferia metropolitana é de 8 vezes a maior entre as áreas metropolitanas do Brasil, conforme registrado na matéria "Brasília sustenta maior renda per capita e tem periferia mais pobre do país" (Jornal Correio Brasiliense, 18/12/2011).

(7) Conceito cunhado por Ribeiro (1995) para caracterizar o processo de urbanização brasileiro excludente nos marcos do que a autora designa como modernização conservadora das décadas de 1960, 1970 e 1980, no contexto do regime militar.

(8) O município de Águas Lindas, integrante da Área Metropolitana de Brasília, é conhecido por ter sido o de maior taxa de crescimento urbano municipal do Brasil nos anos 1990 e por alcançar índices alarmantes de violência urbana no mesmo período.

(9) Os relatórios das últimas missões de especialistas estrangeiros enviados pela Unesco para avaliar as condições de preservação de Brasília como patrimônio cultural da humanidade fazem inúmeros alertas quanto a ameaças que comprometem o tombamento.

(10) Utilizaremos o critério definido em estudo da Codeplan, de dezembro de 2014, que define a Área Metropolitana de Brasília como constituída por 12 municípios adjacentes ao território do DF, a saber: Planaltina de Goiás, Formosa, Padre Bernardo, Águas Lindas, Valparaíso, Novo Gama, Cidade Ocidental, Cristalina, Santo Antônio do Descoberto, Luziânia, Alexânia e Brasília. 
(11) Foram implantados nos últimos vintes anos por sucessivos governos do Distrito Federal programas de Desenvolvimento Econômico (Pró-DF) que consistem basicamente na venda subsidiada de terrenos em áreas públicas nas cidades satélites do Distrito Federal como política de apoio à montagem de pequenas e médias empresas e atividades industriais, como serralherias, marcenarias, confecções, etc.

(12) Entendido como ausência física na urbanização de uma atividade econômica que foi parca e insuficientemente preenchida por atividades de serviços, portanto, não obstante a existência de setores urbanos com destinação industrial, persiste o vazio dessa atividade fundamental da economia moderna, fazendo com que boa parte dos produtos industriais consumidos no Distrito Federal seja importado das áreas industrializadas do País, notadamente o Sudeste. Mais do que isso, em anos recentes o setor destinado a indústrias na Cidade do Gama teve alterada sua destinação no Plano Diretor Local para residencial multifamiliar abrigando hoje inúmeros condomínios verticais de apartamentos sem que houvesse uma destinação alternativa de área para instalação de indústrias.

(13) Veja-se a respeito matéria intitulada "Protesto contra aumento da passagem bloqueia via marginal da BR-070" (jornal Correio Brasiliense, de 9/11/2015).

(14) Professor de Economia e ex-reitor da Universidade, atualmente Senador da República.

(15) O "homem lento" é personagem elaborada por Santos (1994) em sua discussão sobre técnica, espaço e tempo. Personifica o homem comum, pobre, do lugar, que, no ambiente das metrópoles emergentes, resiste às forças verticais, externas, da globalização.

(16) Henri Lefebvre, filósofo e sociólogo francês, realizou inúmeros estudos referentes ao espaço urbano notadamente obras de referência como Le Droit à La Ville (1968) e La Revolution Urbaine (1970), nas quais analisa a influência do sistema econômico capitalista no espaço urbano, com base na necessidade do poder industrial de "modelar" a cidade de acordo com os seus interesses, mas sem excluir a influência de outros agentes sociais.

(17) A Lebre e a Tartaruga é uma das Fábulas de Esopo, que foi posteriormente recontada por La Fontaine, na qual uma lenta tartaruga ganha a corrida de uma veloz lebre.

(18) Fundista e velocista são duas categorias utilizadas nos esportes olímpicos: o fundista percorre longas distâncias a ritmos mais lentos, e o velocista ao contrário percorre curtas distâncias em corrida veloz.

(19) Esse conceito tem inspiração na concepção de cidade metropolitana impulsionada pelo arquiteto Zezéu Ribeiro que, na condição de deputado federal (PT/BA) e presidente da Comissão de Desenvolvimento Urbano da Câmara dos Deputados, liderou a construção da Lei do Estatuto da Metrópole, sancionada em janeiro de 2015. Reconhecemos e homenageamos neste texto a contribuição fundamental de Zezéu, falecido em 2015. 


\section{Referências}

BICCA, P. (1985). “Brasília: mitos e realidades". In: PAVIANI, A. (org.). Brasília, ideologia e realidade: o espaço urbano em questão. São Paulo, Projeto.

CODEPLAN - Companhia de Desenvolvimento do Planalto/GDF (2003). Brasília e sua região polarizada: perfil socioeconômico e demográfico da população. Relações entre o Distrito Federal e entorno. Brasília, Codeplan.

(2014). Delimitação do Espaço Metropolitano de Brasília (Área Metropolitana de Brasília). Nota Técnica $1 / 2014$.

COSTA, L. (1986). Brasília revisitada: 1985/1987. Brasília, Complementação, Preservação, Adensamento e Expansão Urbana.

COUTO, R. et al.; TIMM, P. C. e DOMINICI, M. C. (orgs.). (1992). Brasília: uma economia forte num meio frágil. Brasília, Codeplan (Série Cadernos Codeplan 2).

DEPHA, CODEPLAN (1991). Brasília: Relatório do Plano Piloto de Brasília/Codeplan.

FERNANDES, F. (1968). Sociedade de classes e subdesenvolvimento. Rio de Janeiro, Zahar.

(1995). “Capitalismo dependente e imperialismo”. In: FERNANDES, F. Em busca do socialismo. Últimos escritos e outros textos. São Paulo, Xamã.

FERREIRA, I. C. B. (1985). “O processo de urbanização e a produção do espaço metropolitano de Brasília”. In: PAVIANI, A. Brasília, Ideologia e Realidade: o espaço urbano em questão. São Paulo, Projeto.

FERREIRA, I. C. B. e STEINBERGER, M. (2005). O modelo de gestão de Brasília e as políticas urbanas nacionais. Cadernos Metrópole. São Paulo, v. 7, n. 14.

HARVEY, D. (2000). Espaços de esperança. São Paulo, Companhia das Letras.

(2013). Rebel Cities: from the right to the city to the urban revolution. Londres/Nova York, Verso.

LEFEBVRE, H. (1968). Le droit à la ville. Paris, Anthropos.

(1970). La révolution urbaine. Paris, Gallimard.

LÖWY, M. (1995). A teoria do desenvolvimento desigual e combinado. Revista Actuel Marx. Paris, n. 18.

MEDEIROS, V. (2014). Urbis Brasiliae: o labirinto das cidades brasileiras. Brasília, EdunB.

OLIVEIRA, F. de. (2003). Crítica à razão dualista / o ornitorrinco. São Paulo, Boitempo.

PAVIANI, A. (1985). “A Metrópole Terciária”. In: PAVIANI, A. (org.). Brasília, Ideologia e Realidade: o espaço urbano em questão. São Paulo, Projeto.

PAVIANI, A. e FERREIRA, I. C. B. (1977). Brasília: organização interna da cidade. Revista Brasileira de Planejamento. Brasília, n. 4.

REIS, N. G. (2009). Sobre a dispersão urbana. São Paulo, Via das Artes.

RIBEIRO, A. C. T. e MACHADO, D. B. P. (1990). Metropolização e rede urbana: perspectivas dos anos 90. Rio de Janeiro, Ippur/UFRJ. 
SANTOS, M. (1994). Técnica, espaço e tempo: globalização e meio técnico-científico informacional. São Paulo, Hucitec.

(2003). Por outra globalização - do pensamento único à consciência universal. Rio de Janeiro, Record.

SCHMIDT, B. V. (1985). "Brasília como centro político". IN: PAVIANI, A. Brasília, Ideologia e Realidade: o espaço urbano em questão. São Paulo, Projeto.

TROTSKY, L. (1977). A história da Revolução Russa. Rio de Janeiro, Paz e Terra.

Texto recebido em $1 \%$ ago/2016

Texto aprovado em $1 \%$ nov/2016 